\title{
MENELISIK KEBUDAYAAN BANTEN MELALUI PEMANFAATAN MEDIA VIRTUAL
}

HERDiN MUHTAROM, SULAEMAN

Received: 11 Maret 2021; Accepted: 20 April 2021; Published:30 Juni 2021

Ed. 2021; 4 (2): 217 - 223

\begin{abstract}
Indonesia has a variety of cultures that are formed from the diversity of ethnicities, languages, and races so that they have a value, characteristics and characteristics that are in accordance with the cultural origins of their respective regions or are often known as regional cultures. This study uses a type of literature study research in the process of obtaining information related to the research title. The purpose of this research is to find out about the process of investigating Banten culture through the use of virtual media in the digitalization era as a medium to preserve the philosophical values contained in the culture in the Banten area. Virtual media in the era of digitalization is very easy to access so that it can provide an understanding process related to a culture by using information and communication technology.
\end{abstract}

Keyword: Indonesia, Culture, Virtual Media.

\section{PENDAHULUAN}

Kebudayaan berasal dari bahasa sanskerta, yaitu buddhayah yang arti lainnya (budi dan akal). Dengan budi dan akal, manusia bisa menciptakan kebudayaan. Dimana kebudayaan itu sendiri adalah hasil dari akal budi yang berupa karya, rasa, dan cipta dalam interaksinya baik dengan alam atau manusia lainnya (SAHADI, 2019). Indonesia memiliki berbagai kebudayaan yang terbentuk dari keanekaragaman suku, bahasa, dan ras sehingga hal tersebut memiliki suatu nilai, ciri khas dan karakteristik yang sesuai dengan asal kebudayaan daerahnya masing-masing atau sering dikenal dengan istilah kebudayaan daerah.

Kebudayaan daerah merupakan budaya yang memiliki nilai aspek dalam kehidupan masyarakat daerah yang terdapat nilai-nilai yang sesuai dengan kearifan lokal daerahnya. Setiap daerahnya tentunya memiliki perbedaan ciri khas yang terdapat pada budayanya. Dengan memiliki banyak keberagaman kebudayaan daerah di Indonesia merupakan kekayaan dan identitas bangsa untuk memajukan kebudayaan nasional. Dalam pembentukan kebudayaan, puncak-puncak kebudayaan daerah sangat penting peranannya. Ini berarti, kita dituntut untuk lebih banyak menggali kebudayaan daerah sehingga proses pertumbuhan kebudayaan nasional semakin terbentuk (NUNDHIR, 1988). Dalam meningkatkan kebudayaan nasional Indonesia sebagai identitas bangsa, peranan budaya daerah menjadi pionir dalam membentuk identitas kebudayaan nasional. Kita sebagai penerus bangsa Indonesia harus memahami dan menelisik kebudayaan daerah 
yang ada di Indonesia melalui media virtual ataupun berkunjung secara langsung untuk melihat keanekaragaman budaya daerah di Indonesia.

Setiap unsur kebudayaan perlu dipertimbangkan untuk dilindungi, dikelola, dan diperkuat (WIDIA, 2019). Setiap daerah di Indonesia harus tetap mempertahankan kebudayaannya terutama dalam arus globalisasi, hal ini tentunya menjadi sebuah tantangan dan solusi dalam mempertahankan kebudayaan daerah Indonesia melalui teknologi media virtual untuk menelisik kebudayaan di setiap daerah Indonesia.

Budaya merupakan identitas bangsa yang harus dihormati dan dijaga serta harus dilestarikan agar kebudayaan bangsa tidak hilang dan menjadi warisan bagi generasi penerus bangsa (NURJAMAN, SUDADIO, \& FATUROHMAN, 2017). Provinsi Banten adalah daerah di Indonesia yang memiliki pontesi budaya yang harus dijaga dan di lestarikan oleh generasi bangsa Indonesia, karena Provinsi Banten memiliki potensi budaya dari segi religiusitas, seni tari, dan tradisi budaya daerahnya. Ragam seni pertunjukan kesenian rakyat Banten, pada umumnya berkembang secara turun-temurun, yang tidak terlepas dari nafas keagamaan serta dalam perjalanannya tidak terlepas dari pengaruh agama Islam, maupun agama lain. Kesenian rakyat yang berkembang di Banten hingga sampai sekarang sangatlah beragam (HAKIKI, 2017).

Masyarakat virtual merupakan masyarakat di era digital yang kini memegang peranan penting dalam menghasilkan dan mempengaruhi relasi sosial (LAIMEHERIWA, 2018). Masyarakat yang sudah memahami pemanfaatan digital sebagai media virtual untuk menelisik kebudayaan melalui pemanfaataan media virtual sebagai sarana media untuk mempelajari dan memahami terkait kebudayaan daerah Provinsi Banten, sehingga generasi penerus bangsa dapat mengembangkan kebudayaannya sehingga tidak menghilangkan nilai-nilai yang terkandung dalam filosofis kebudayaan tersebut.

Tujuan dalam penelitian ini untuk mengetahui terkait proses menelisik kebudayaan Banten melalui pemanfaatan media virtual di era digitalisasi sebagai media untuk melestarikan nilai-nilai filosofis yang terdapat pada kebudayaan di daerah Banten.

\section{METODE PENELITIAN}

Penelitian ini menggunakan jenis penelitian studi literature dalam proses untuk mendapatkan informasi yang berkaitan dengan judul penelitian. Adapun langkahlangkah dalam menggunakan penelitian studi literature yaitu pertama, mencari dan menemukan sumber referensi baik dari artikel ilmiah, maupun buku yang terdapat pada Google Schoolar serta foto, dan sumber internet lainna yang berkaitan dengan judul dalam penelitian. kedua, kemudian menganalisis terkait sumber penelitian yang sesuai dengan judul dalam penelitian, dan merealisasikan sumber penelitian melalui analisis deskriptif.

\section{HASIL DAN PEMBAHASAN \\ Sejarah dan Kebudayaan Banten}

Banten memiliki sejarah yang panjang dan menyandang nama besar. Kebesaran Banten mulai terdengar terutama ketika ia menjadi pelabuhan internasional. Kondisi Banten Lama kurang lebih dari 10 tahun yang lalu, tahun 1999, cukup memprihatinkan (SAEFULLAH, 2009). Pada abad ke-17 Masehi, Provinsi Banten adalah salah satu pusat perniagaan penting dalam jalur perdagangan internasional 
di Asia. Dalam pola administrasi pada saat itu sangat menunjang dalam tumbuhnya perekonomian masyarakat. Perkembangan sejarah provinsi Banten yang memiliki keterkaitan kesejarahan yang sangat panjang menimbulkan banyak sekali akulturasi budaya, namun tidak hanya adanya akulturasi budaya yang terjadi. Pada perkembangan kebudayaan Banten menjadikan budaya di Banten berkembang dengan pesat dan memiliki nilai filosofi dari setiap budaya yang ada.

Kebudayaan Banten adalah sebagian dari pola dinamka budaya nasional yang telah berkembang melalui pola ruang dan waktu. Provinsi Banten telah memahami pola bentuk kebudayaan melalui perkembangan sejarah yang panjang. Seni budaya Banten merupakan kesenian peninggalan sebelum Islam dan dipadu atau diwarnai dengan agama Islam. Misalnya arsitektur masjid dengan tiga tingkat sebagai simbolisasi Iman, Islam, Ihsan, atau Syari'at, Tharekat, Hakekat (SAID, 2017).

Kebudayaan dan tradisi Banten yang dimiliki oleh 4 Kabupaten dan 3 Kota yaitu terdapat pada Kabupaten Tanggerang, Kabupaten Serang, Kabupaten Pandeglang, dan Kabupaten Lebak serta Kota Serang, dan Kota Cilegon. Memiliki ciri khas terkait kebudayaan dan tradisi di setiap daerahnya. Adapun tradisi dan kebudayaan Banten terbagi menjadi empat jenis kesenian Tradisional Banten yaitu:

\section{a. Seni Tradisional Keagamaan,}

di antaranya yaitu Rampak Bedug, Terebang Gede, Qasidah, Saman, Yalil.

\section{b. Seni Tradisonal yang Berkaitan dengan Budaya Islam, yaitu Debus, Patingtung dan Rudat.}

\section{c. Seni Tradisional Banten Lama, yaitu}

Angklung Buhun, Dog-dog Lojor,

Bendrong Lesung, dan Beluk

\section{d. Seni Tradisional Akulturasi Budaya Banten dengan Budaya Luar Banten, Yaitu Kuda Lumping, Gambang Kromong, dan Cokek.}

Dari berbagai kebudayaan, Tradisi, dan Kesenian Tradisional yang di miliki oleh daerah Banten menunjukan peran masyarakat Banten yang memiliki pola berpikir. Imajinasi, dan daya kreatifitas yang sangat tinggi, hal tersebut menunjukan bahwa kekayaan dalam kebudayaan yang di miliki oleh provinsi Banten sebagai identitas budaya nasional Indonesia, harus dibina dan terus dikembangkan terutama dalam mengembangkan sebuah identitas daerah dan sebagai perkembangan pariwisata setempat.

\section{Pemanfaatan Media Virtual dan Jenis Media Virtual dalam Menelisik Kebudayaan Banten}

Perkembangan zaman akan merubah peradaban manusia dalam melakukan segala aktivitas kehidupan sehari-hari. Hal ini berdasarkan adanya perkembangan teknologi dalam kehidupan manusia sehingga memudahkan manusia untuk mendapatkan informasi melalui teknologi yang memadai dalam mengaskes sebuah informasi yang relevan. Perkembangan teknologi memberikan dampak positif dan dampak negative terutama dalam perkembangan peradaban manusia. Melalui teknologi informasi dan komunikasi memudahkan manusia untuk mengaskes segala informasi yang ingin diketahui, namun dampak negative yang ditimbulkan oleh teknologi yaitu sifat individualistic pada masyarakat sehingga menyebabkan kurangnya interaksi. Sehingga menimbulkan permasalahan baru atau yang sering dikenal dengan budaya individual 
masyarakat. Perkembangan yang terjadi dengan cepat di bidang komunikasi membuat para ahli menyebutnya sebagai revolusi komunikasi. Perubahan yang cepatini didorong oleh adanya berbagai penemuan di bidang teknologi sehingga apa yang dulu merupakan kendala dalam kegiatan komunikasi, sekarang sudah terbuka lebar (ZAMRONI, 2017).

Perkembangan teknologi dan informasi tidak hanya memudahkan dalam pola interaksi masyarakat, tetapi melalui teknologi dan informasi merubah pola perkembangan dalam model pembelajaran melalui pemanfaatan media virtual. Media Virtual adalah sistem media digital dalam teknologi komputer yang berfungsi untuk menyampaikan sistem pembelajaran berupa metode atau model eksperimen atau media virtual merupakan model pembelajaran yang berbasiskan media teknologi informasi dan komunikasi.

Dalam perkembangan jaman media virtual mudah untuk digunakan dalam sistem pembelajaran, dikarenakan menggunakan elemen media yang mudah dan tidak asing digunakan oleh semua kalangan masyarakat. Melalui media virtual juga memberikan efektifitas kepada pengguna teknologi untuk memanfaatkan dan menggunakan secara bijak dalam menggunakan teknologi informasi dan komunikasi. Pemanfaatan media virtual dalam menelisik sebuah kebudayaan daerah sangat mudah, sehingga generasi muda dapat mempelajari kebudayaan di mana saja, dan kapan saja. Dengan melalui pemanfaatan media virtual sebagai media untuk menelisik kebudayaan dapat memberikan kemudahan dalam mengaskes informasi terkait kebudayaan yang akan dicari.
Peran media virtual dalam menelisik kebudayaan di Indonesia sangat berpengaruh penting untuk melestrikan kebudayaan tersebut dengan melihat, mengamati, dan mengimplementasikan nilai-nilai kebudayaan melalui media virtual, akan dapat membuka pola pikir generasi muda untuk tetap menjaga dan melestarikan kebudayaan daerahnya sebagai identitas budaya nasional Indonesia. Media virtual dalam menelisik kebudayaan banten juga dapat melalui media-media virtual yang tidak asing digunakan oleh generasi muda, hal tersebut untuk dapat memberikan efektivitas dalam melestarikan kebudayaan Banten melalui media virtual.

Dalam menggunakan media virtual untuk menelisik kebudayaan Banten terbagi menjadi beberapa bagian media virtual yaitu :

\section{Media virtual berbasis Jejaring Sosial}

Media jejaring sosial yang sangat mudah di akses dan sering digunakan oleh generasi muda sehingga dapat menelisik kebudayaan budaya Banten dengan mudah dan dapat di askes kapan pun saja. Dengan melalui media virtual yang berbasis jejaringan sosial akan lebih mudah untuk menginformasikan kebudayaan Banten dengan mudah. Karena melalui media sosial akan lebih memudahkan memberikan informasi terkait kebudayaan Banten. Salah satunya yaitu dengan media sosial untuk menelisik sebuah kebudayaan Banten. Salah satu contohnya media virtual yang berbasis jejraing sosial untuk proses menelisik kebudayaan Banten yaitu melalui media sosial Instagram. Twiteer, dan Facebook. 


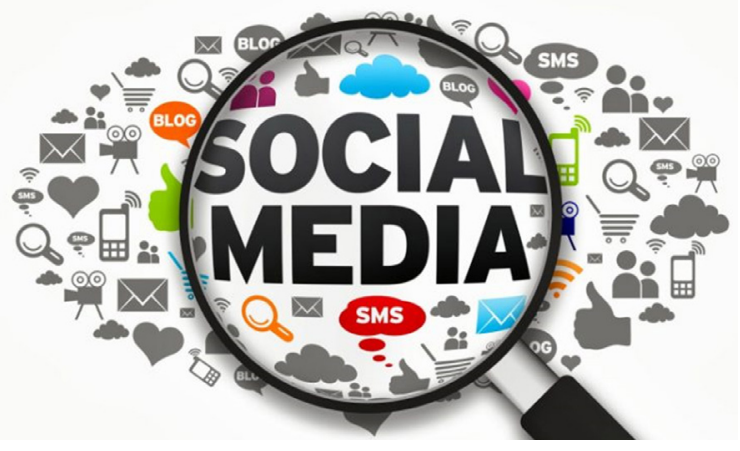

Gambar 1. Sosial Media sebagai Media Virtual dalam Menelisik Kebudayaan Banten

Melalui media jejaring sosial untuk menelisik kebudayaan Banten dengan menggunakan aplikasi yang mudah digunakan oleh generasi muda sehingga mereka mudah untuk melakukan proses menelisik kebudayaan dengan aplikasi yang sering di gunakan. Melalui media jejaring sosial juga dapat mudah melakukan share informasi kepada yang lainnya sehingga dapat menimbulkan proses interaksi pada saat menelisik kebudayaan Banten.

\section{Media Audiovisual}

Media untuk menelisik kebudayaan Banten dapat diaskes melalui media berbagi yang memiliki fasilitas penggunanya untuk berbagai media yang terdiri dari suara, gambar, dan file yang dapat di askes melalui media berbagi untuk proses menelisik kebudayaan Banten.

Dengan menggunakan sistem media audiovisual dapat memudahkan proses pemahaman generasi muda dalam proses menelisik kebudayaan Banten. Adapun media audiovisual yang sering digunakan yaitu media aplikasi Youtube.

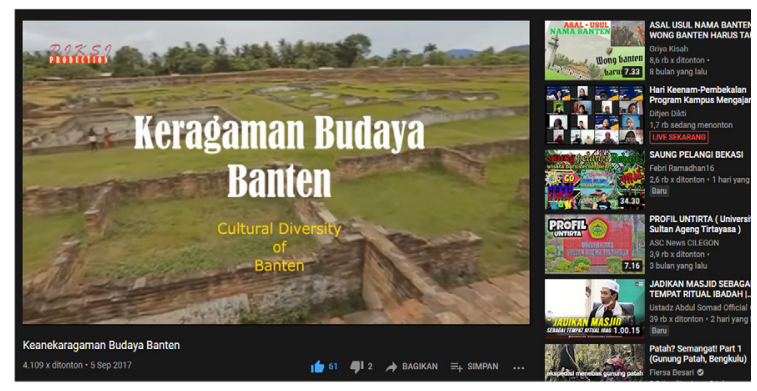

Gambar 2. Youtube sebagai Media Virtual dalam Menelisik Kebudayaan Banten.

Menelisik dengan menggunakan media Youtube dapat memudahkan proses menelisik kebudayaan Banten, karena dengan media audiovisual dapat memberikan audio dan gambar terkait kebudayaan Banten. Hal tersebut akan memudahkan generasi muda dalam memahami nilai-nilai atau filosofi yang terkandung dalam kebudayaan Banten. Melalui media Youtube yang mudah digunakan oleh semua kalangan masyarakat dalam proses menelisik kebudayaan membuat proses pemahaman mengenai kebudayaan Banten dapat lebih mudah. Dalam proses menggunakan media virtual berbasiskan media audiovisual yaitu dengan mengakses aplikasi Youtube kemudian mencari kata kunci terkait kebudayaan Banten. Dengan menggunakan media audiovisual melalui aplikasi Youtube dapat memberikan pola pembelajaran kepada masyarakat untuk proses menelisik kebudayaan Banten.

\section{Media Jurnal atau Tulisan}

Menelisik kebudayaan Banten juga dapatdi askes melalui media jurnal atau tulisan yang berkaitan dengan kebudayaan Banten. Hal tersebut untuk mengetahui proses kebenaran yang berdasarkan asas akademik untuk mengetahui terkait kebudayaan Banten. Melalui tulisan atau jurnal untuk menambah wawasan generasi muda dalam proses 
menelisik kebudayaan Banten melalui media virtual.

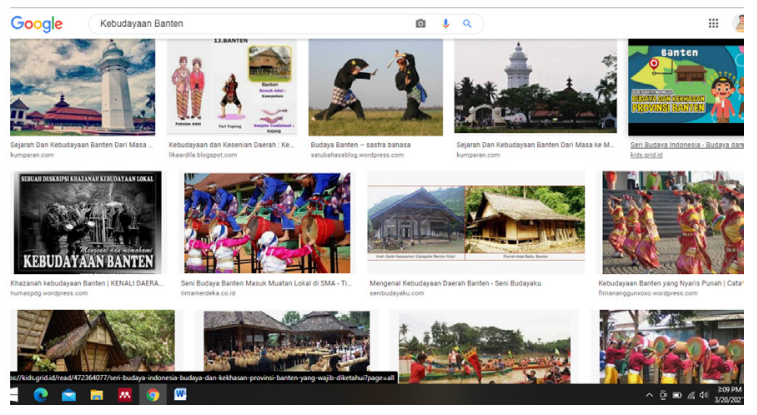

Gambar 3. Google sebagai Media Virtual dalam Menelisik Kebudayaan Banten.

Untuk mengaskes informasi yang tepat terkait kebudayan Banten yaitu kita dapat mencari pada sumber referensi yang dipercayai sesuai asas akademik. Karena jika kita salah mengambil sumber referensi terkait kebudayan Banten kita dapat mengurangi dan kurang memahami terkait sejarah ataupun nilai filosofi kebudayaan Banten. Generasi muda untuk mendapat informasi yang tepat terkait proses menelisik kebudayaan melalui media virtual terutama dalam media jurnal atau tulisan melalui Website Google Schoolar. Karena website tersebut memiliki sumber referensi yang terpercayai.

\section{KESIMPULAN}

Perkembangan teknologi dan informasi dapat memberikan jenis media virtual terutama dalam menelisik kebudayaan Banten, sehingga dapat memberikan suasana baru dalam proses mempelajari kebudayaan Banten melalui media virtual. Dengan memanfaatkan media virtual berbasiskan teknologi informasi dan komunikasi dapat memudahkan generasi muda dalam menggunakan media virtual tersebut. Media virtual merupakan kegiatan memahami suatu hal melalui media yang berbasiskan teknologi informasi dan komunikasi. Menelisik kebudayaan Banten melalui media virtual bertujuan untuk memahami nilai-nilai filosofi terkait kebudayaan Banten sehingga dengan menggunakan media virtual yang sering digunakan oleh generasi muda dapat memberikan perubahan pola pikir generasi muda untuk terus mempelajari kebudayaan dengan menggunakan media virtual. Media virtual di era digitalisasi sangat mudah di askes sehingga dapat memberikan proses pemahaman terkait sebuah kebudayaan dengan menggunakan teknologi informasi dan komunikasi.

\section{DAFTAR PUSTAKA}

HAKIKI, K. M.

2017. DEBUS BANTEN: Pergeseran

Otentisitas dan Negosiasi Islam-

Budaya Lokal. Kalam, 7(1), 1. https://

doi.org/10.24042/klm.v7i1.163

LAIMEHERIWA, M. C.

2018. Masyarakat Virtual, Mitos Dan Perilaku Konsumtif. KENOSIS: Jurnal Kajian Teologi, 4(1), 23-38.https:/ / doi. org/10.37196/kenosis.v4i1.49

NundHIR, A.

1988. Perspektif Wayang Dalam Pertumbuban Kebudayaan Nasional. Jurnal

Cakrawala Pendidikan, 1(1), 92-111. https://doi.org/10.21831/ cp.v1i1.7430

Nurjaman, F., Sudadio, S., \& FATUROHMAN, N.

2017. Implementasi Pelatiban Tari Daerah dalam Melestarikan Tarian Banten di Sanggar Raksa Budaya Kota Serang. Journal of Nonformal Education and Community Empowerment, 1(2), 152-160. https://doi.org/10.15294/ plsv1i2.19414 


\section{SAEFullah, A.}

2009. Membaca Sejarah Banten dari

Sumber Asing: Review Buku Banten,

Sejarab dan Peradaban Abad X-XVII

Karya Claude Guillot*). Jurnal Lektur

Keagamaan Jurnal Lektur

Keagamaan, 7(2), 313-330.

SAHADI.

2019. Pelestarian Kebudayaan Daerah melalui

Kesenian Dodod di Kampung Pamatang

Desa Mekarwangi Kecamatan Saketi

Kabupaten Pandeglang. Dinamika:

Jurnal Ilmiah Ilmu Administrasi

Negara, 6(4), 315-326.

\section{SAID, H. A.}

2017. Islam dan Budaya Di Banten:

Menelisik Tradisi Debus Dan Maulid.

Kalam, 10(1), 109. https://doi.

org/10.24042/klm.v10i1.338

\section{WiDIA, I. KETUT.}

2019. Pemajuan Kebudayaan Dalam

Rangka Menjadikan Kalimantan

Timur Sebagai Tujuan Wisata

Berkelas Dunia. Ganaya: Jurnal

Ilmu Sosial Dan Humaniora, 2(2), 10-14. Retrieved from http:// jayapanguspress.penerbit.org/index. $\mathrm{php} /$ ganaya/article/view/366

\section{ZAMRONI, M.}

2017. Perkembangan Teknologi Komunikasi

Dan Dampaknya Terbadap Kebidupan. Jurnal Pendidikan, X(2), 195-211. 